Estudios Constitucionales, Año 8, No 1, 2010, pp. 117 - 136.

ISSN 0718-0195

Centro de Estudios Constitucionales de Chile Universidad de Talca

"Obligaciones internacionales y control de convencionalidad"

Néstor Pedro Sagüés

\title{
OBLIGACIONES INTERNACIONALES Y CONTROL DE CONVENCIONALIDAD ${ }^{1}$ INTERNATIONAL OBLIGATIONS AND "CONVENTIONALITY CONTROL"
}

\author{
Néstor Pedro SAgÜÉs ${ }^{2}$ \\ Profesor Universidad de Buenos Aires \\ y Universidad Católica Argentina. \\ npsagues@gmail.com
}

RESUMEN: El "control de convencionalidad" establecido por la Corte Interamericana de Derechos Humanos en el caso "Almonacid Arellano" y completado por otros, especialmente "Trabajadores cesados del Congreso", ordena a los jueces nacionales reputar inválidas a las normas internas (incluida la Constitución) opuestas a la Convención Americana sobre Derechos Humanos, y a la interpretación dada a ésta por la Corte Interamericana. Es un instrumento eficaz para construir un ius commune interamericano en materia de derechos personales y constitucionales. Su éxito dependerá del acierto de las sentencias de la Corte Interamericana, y de la voluntad de seguimiento de los tribunales nacionales.

ABSTRACT: The "conventionality control" ordered by the Interamerican Court of Human Rights, specially in the cases "Almonacid Arellano" and "Trabajadores Cesados del Congreso", disposes that the national judges must consider not valid the domestic norms that infringe the American Convention of Human Rights, or the jurisprudence of the Interamerican Court. That control is an important instrument in order to edify an interamerican ius commune about human and constitutional rights. Its success depends on the legitimacy of the resolutions of the Interamerican Court, and the disposition of the national tribunals.

PalabRas CLAVE: Control de convencionalidad. Modelos. Corte Interamericana de Derechos Humanos. Jueces nacionales. Convención Americana de Derechos Humanos. Supremacía constitucional. Ius commune. Normas nacionales. Resultados del control de convencionalidad. Control de constitucionalidad y control de convencionalidad.

KEY WORDS: "Conventionality control". Models. Interamerican Court of Human Rights. National judges. American Convention of Human Rights. Constitutional supremacy. Ius commune. National norms. Results of the "conventionality control". Judicial constitutional review and "conventionality control".

\footnotetext{
${ }^{1}$ Presentado el 6 de marzo de 2010, aprobado el 24 de marzo de 2010. El presente trabajo se inserta en el programa de investigaciones del Centro Interdisciplinario de Derecho Procesal Constitucional, de la Facultad de Derecho y Ciencias Sociales del Rosario, de la Universidad Católica Argentina.

${ }^{2}$ Doctor en derecho, Profesor de derecho Constitucional y Procesal Constitucional de la Universidad Católica Argentina y Universidad de Buenos Aires. Presidente del Instituto Iberoamericano de Derecho Procesal Constitucional.
} 


\section{INTRODUCCIÓN. FormULACIÓN DEL CONTROL DE CONVENCIONALIDAD}

Los arts. $1^{\circ}$ y $2^{\circ}$ de la Convención Americana sobre Derechos Humanos, o Pacto de San José de Costa Rica, sientan "deberes" específicos para los Estados a ella adheridos. El primero, esencialmente, establece dos: a) respetar los derechos de la Convención, y b) garantizarlos, sin discriminación alguna. A su turno, el art. $2^{\circ}$ les obliga a adoptar "disposiciones legislativas o de otro carácter" necesarias para efectivizar aquella garantía. Aquí se alude al "efecto útil" que debe tener el Pacto.

En el escenario interamericano, y con algunos antecedentes precisos en votos aislados emitidos en otros pronunciamientos, ${ }^{3}$ la sentencia pronunciada por la Corte Interamericana de Derechos Humanos en el caso "Almonacid Arellano y otros vs. Gobierno de Chile", del 26 de septiembre de 2006, definió claramente, dentro del marco de vigencia de la Convención Americana sobre derechos humanos, el "control de convencionalidad" a practicarse por los jueces nacionales. ${ }^{4}$

Dicho "control de convencionalidad" se perfila como una herramienta sumamente eficaz para el respeto, la garantía y la efectivización de los derechos descritos por el Pacto. Concomitantemente, también es un instrumento de sumo interés para construir un ius commune interamericano, en materia de derechos personales y constitucionales.

Conviene transcribir literalmente, primero, el texto del veredicto, tal como surge del considerando 124: "La Corte es consciente que los jueces y tribunales internos están sujetos al imperio de la ley y, por ello, están obligados a aplicar las disposiciones vigentes en el ordenamiento jurídico. Pero cuando un Estado ha ratificado un tratado internacional como la Convención Americana, sus jueces, como parte del aparato del Estado, también están sometidos a ella, lo que obliga a velar porque los efectos de las disposiciones de la Convención no se vean mermadas por la aplicación de leyes contrarias a su objeto y fin, y que desde un inicio carecen de efectos juridicos. En otras palabras, el Poder Judicial debe ejercer una especie de "control de convencionalidad"

\footnotetext{
${ }^{3}$ Ver por ejemplo los votos singulares del juez de la Corte Interamericana de Derechos Humanos, Sergio García Ramírez, en los casos "Myrna Mack Chang” (25/11/2003), y “Tibi” (7/9/2004). Cfr. García Ramírez, Sergio y Morales, Julieta, "La jurisprudencia de la Corte Interamericana de Derechos Humanos en el período 2007/2009", Anuario Iberoamericano de Justicia Constitucional, Centro de Estudios Políticos y Constitucionales, núm. 13, Madrid, 2009, pp. 503 y 504. Pero algunas veces se hace remontar la gestación del control de convencionalidad a lustros atrás. Ver Rey Cantor, Ernesto, (2008), pp. 51 y ss.

${ }^{4}$ Sobre el tema, cfr., entre otros, Hitters, Juan Carlos, (2008), p. 1169; Albaneses, Susana, (2008), pp. 22 y ss., con mención de los antecedentes en el derecho comunitario europeo y mención del libro de SuDRé, Frédéric. (2004), p. 207; Rey CanToR, Ernesto, (2008), nota 1, passim. El caso "Almonacid Arellano" puede leerse por ejemplo en Revista de Derecho, Montevideo, Universidad Católica del Uruguay, No 02, 2007, pp. 217 y ss.
} 
entre las normas juridicas internas que aplican en los casos concretos y la Convención Americana sobre Derechos Humanos. En esa tarea, el Poder Judicial debe tener en cuenta no solamente el tratado, sino también la interpretación que del mismo ha hecho la Corte Interamericana, intérprete última de la Convención Americana".

El considerando 125 agrega un dato complementario: "En esa misma línea de ideas, esta Corte ha establecido que '(s)egún el derecho internacional las obligaciones que éste impone deben ser cumplidas de buena fe y no puede invocarse para su incumplimiento el derecho interno'. Esta regla ha sido codificada en el artículo 27 de la Convención de Viena sobre el Derecho de los Tratados, de 1969".

La doctrina fue repetida, sin mayores variantes, en los casos "La Cantuta vs. Perú", sentencia de 29 de noviembre de 2006, consid. 173, y "Boyce y otros vs. Barbados", de 20 de noviembre de 2007, consid. 78. Pero en el caso "Trabajadores Cesados del Congreso (Aguado Alfaro y otros) vs. Perú", de 24 de noviembre de 2006, consid. 128, la Corte Interamericana formuló algunas especificaciones y adiciones. Allí dijo: "Cuando un Estado ha ratificado un tratado internacional como la Convención Americana, sus jueces están sometidos a ella, lo que les obliga a velar porque el efecto útil de la Convención no se vea mermado o anulado por la aplicación de leyes contrarias a sus disposiciones, objeto y fin. En otras palabras, los órganos del Poder Judicial deben ejercer no sólo un control de constitucionalidad, sino también de convencionalidad, ex officio, entre las normas internas y la Convención Americana, evidentemente en el marco de sus respectivas competencias y de las regulaciones procesales pertinentes. Esta función no debe quedar limitada exclusivamente por las manifestaciones o actos de los accionantes en cada caso concreto, aunque tampoco implica que ese control deba ejercerse siempre, sin considerar otros supuestos formales y materiales de admisibilidad y procedencia de este tipo de acciones".

Más recientemente, por ejemplo en "Fermín Ramírez" y "Raxcacó Reyes vs. Guatemala" (considerando 63), de 9 de mayo de 2008, se volvió a ratificar esta doctrina.

Cabe detenerse en el análisis de los distintos subtemas que plantean estos pronunciamientos, que deben enlazarse entre sí para lograr una interpretación conjunta del "control de convencionalidad". Desde ya cabe anticipar que el criterio de la Corte Interamericana no es siempre lineal o uniforme, y que quizá contiene algunas desprolijidades preocupantes.

Aun así, con esos defectos, la doctrina del "control de convencionalidad" se presenta como una de las herramientas más prácticas e inmediatas para elaborar un ius commune en la región, en particular en cuanto una visión homogénea en materia de derechos humanos fundamentales, como lo anticipara Pablo Pérez Tremps. ${ }^{5}$

${ }^{5}$ Pérez Tremps, Pablo, (2005), p. 84. 


\section{De “UNA especie De CONTROl”, AL “CONTROl” Liso y lLANo}

Preliminarmente cabe constatar que mientras en "Almonacid Arellano vs. Chile" la Corte habla de "una especie de control de convencionalidad", en "Trabajadores cesados del Congreso vs. Perú" alude directamente al control de convencionalidad. En la última sentencia, en síntesis, el instituto de referencia es presentado, sin más, como un acto de revisión o fiscalización de la sumisión de las normas nacionales, a la Convención Americana de Derechos Humanos, y a la exégesis que a este instrumento da la Corte Interamericana de Derechos Humanos.

\section{FUNDAMENTOS JURÍDICOS DEL CONTROL}

Las razones dadas por la Corte Interamericana para sentar el control de convencionalidad son dos, y ambas de derecho internacional: (i) las obligaciones internacionales deben ser cumplidas de buena fe; (ii) no es posible alegar el derecho interno para incumplirlas, conforme el art. 27 de la Convención de Viena sobre el derecho de los tratados.

Aquí conviene recordar dos temas. El primero es que, para muchos, estas reglas significan una seria restricción a la soberanía de los Estados. Sobre el punto, cabe tener presente, sin embargo, que en la cuna misma de la doctrina de la soberanía (estamos hablando del siglo XVI), Jean Bodin, que la describe y enuncia en sus rasgos esenciales, advertía que la soberanía, aun entrevista como "poder absoluto y perpetuo" del Estado, de todos modos admitía como tope que el príncipe soberano estaba obligado (como también Dios) a cumplir sus promesas, aclarando que no había mayor delito para un rey, que ser perjuro. ${ }^{6}$

El segundo comentario es que la Convención de Viena sobre el derecho de los tratados permite en su art. 47 al Estado -como excepción- alegar su derecho interno para eximirse del cumplimiento de un tratado, si su consentimiento al elaborarlo hubiera sido viciado por una violación manifiesta, en materia de competencia para celebrar el tratado, y ello afectare a una norma fundamental de ese derecho interno.

\section{IV. ¿QUIÉN DEBE PRACTICAR EL “CONTROL DE CONVENCIONALIDAD”?}

Desde luego, la Corte Interamericana hace control de convencionalidad cuando en sus veredictos ella descarta normas locales, incluso constitucionales, opuestas al Pacto de San José de Costa Rica. A eso se lo ha denominado "control de convencionalidad en sede internacional", para diferenciarlo del que imperativamente asigna a los jueces domésticos en "Almonacid Arellano" y los demás fallos

${ }^{6}$ SAGỨés Néstor Pedro, (1978), pp. 76 y 77. 
posteriores que ya mencionamos, que aluden al "control de convencionalidad en sede nacional". 7 Es a este último al que nos dedicaremos de aquí en más.

Aparentemente, en "Almonacid Arellano" y en las sentencias que lo siguen, la Corte Interamericana encomienda el control de convencionalidad a los jueces domésticos del Poder Judicial. Sin embargo, razones derivadas del principio de analogía, del argumento teleológico y del argumento "a fortiori", llevan a concluir que esa directriz obliga también a los jueces de un Tribunal Constitucional extrapoder (cuando así ha sido diseñado por la constitución), en las causas sometidas a su decisión. Si de lo que se trata es de asegurar el "efecto útil" del Pacto de San José de Costa Rica, contra normas internas que se le opongan, en los procesos respectivos, esa misión de aplicar sin cortapisas el derecho del Pacto tiene que involucrar, igualmente, a las cortes y tribunales constitucionales, aunque en algunos casos no pertenezcan al Poder Judicial y operen como entes constitucionales autónomos, o extra-poder.

El mensaje de "Trabajadores cesados del Congreso", parece indicar que el juez que está habilitado para ejercer el control de constitucionalidad, debe asimismo practicar el control de convencionalidad. El fallo le reclama, por cierto, tal doble control.

El asunto puede no ofrecer problemas en una nación que posea un sistema de control difuso o desconcentrado de constitucionalidad, como Argentina, en el que todo juez es competente para ejercitar tal revisión. Tampoco hay dificultades en Estados que practican un régimen "mixto", dual o híbrido, en el que todos los jueces comunes tratan temas constitucionales, en orden a inaplicar las normas opuestas a la Constitución en los procesos que deben resolver, pero también lo hacen organismos especializados (cortes o tribunales constitucionales específicos, salas constitucionales), en ciertos supuestos.

Ahora bien, ¿qué ocurre si según el régimen vigente en un país determinado, hay jueces del Poder Judicial no habilitados para ejercer el control de constitucionalidad, el que se reserva, por ejemplo, solamente a su Corte Suprema, o a una Sala Constitucional de la Corte Suprema? (control total o parcialmente concentrado: con ciertas variantes, casos del Uruguay, México o Costa Rica, v. gr.).

Parte de la doctrina sienta la tesis del control de convencionalidad a realizar por los jueces nacionales como control difuso, o desconcentrado, vale decir, que resultaría obligatorio para todos ellos. ${ }^{8}$

\footnotetext{
${ }^{7}$ Rey Cantor, Ernesto, (2008), nota 1, pp. 48 y 49.

${ }^{8}$ Rey Cantor, Ernesto, (2008), nota 1, p. 201. En el sentido que el control de convencionalidad operado en el ámbito nacional es difuso, ver García Ramírez, Sergio, (2009), p. 344.
} 
Aunque la Corte Interamericana no resuelve explícitamente la incógnita, la misma sentencia de "Trabajadores cesados del Congreso" alude, para practicar el "control de convencionalidad", a la satisfacción de los recaudos vigentes formales de admisibilidad, y otros materiales de procedencia, todo ello "en el marco de sus respectivas competencias y de las regulaciones procesales pertinentes". Cabría concluir, entonces, que en un Estado como el que aludimos, el juez del Poder Judicial incompetente para realizar el control de constitucionalidad, que considere que puede haber en un caso sometido a su decisión un problema de "convencionalidad", deberá remitir los autos al tribunal habilitado para ejercer el control de constitucionalidad, mediante el conducto procesal adecuado, a fin de que sea éste quien realice eventualmente la simultánea revisión de convencionalidad.

Sin embargo, ocurre que en determinados países algunos jueces comunes no realizan control de constitucionalidad, y no siempre hay una escalera para remontar el caso al organismo que sí puede hacerlo. Ante ello, el problema debe resolverse de un modo razonable y en su caso, creativo. Lo importante es, desde luego, que en tales hipótesis no se desemboque en una vía muerta y aceptar que no haya, en la esfera nacional, control de convencionalidad. Éste siempre tendrá que practicarse, so pena de desobedecer las directivas de la Corte Interamericana de Derechos Humanos.

En definitiva, si en un Estado concreto hay jueces inhabilitados por el ordenamiento local para verificar el control de constitucionalidad (y, por ende, en principio, el de convencionalidad), y no existen caminos procesales para remitir la litis a quien sí está autorizado a practicarlo, caben estas alternativas: (i) como ruta más preferible, consumar una reforma, constitucional o legislativa según el caso, para resolver el problema; (ii) mientras ella no se practique, reconocer pretorianamente a todos los jueces aptitud para instrumentar el control de convencionalidad (solución del "control difuso"), o (iii) diseñar - pretorianamente también- un mecanismo de elevación del caso al órgano constitucionalmente programado para operar el control de constitucionalidad. Estas vías pretorianas no resultan anómalas para asegurar el efecto útil (effet utile) de la Convención Americana sobre Derechos Humanos, a tenor del art. $2^{\circ}$ de la misma. ${ }^{9} Y$ de ellas, personalmente nos parece preferible la última, que es la más respetuosa de la opción hecha por el constituyente doméstico para erigir un sistema de control de constitucionalidad.

\footnotetext{
${ }_{9}^{9}$ Convención Americana de Derechos Humanos (Pacto de San José de Costa Rica), art. 20: "Si el ejercicio de los derechos y libertades mencionados en el art. $1^{\circ}$ no estuvieren ya garantizados por disposiciones legislativas o de otro carácter, los Estados partes se comprometen a adoptar, con arreglo a sus procedimientos constitucionales y a las disposiciones de esta Convención, las medidas legislativas o de otro carácter que fueren necesarias para hacer efectivos tales derechos y libertades".
} 


\section{V. ¿CÓMO Y CUÁNDO SE REALIZA EL CONTROL \\ DE CONVENCIONALIDAD EN EL ÁMBITO NACIONAL?}

La sentencia dictada en "Trabajadores Cesados del Congreso vs. Perú” aclaró el fallo "Almonacid Arellano", en el sentido que el control de convencionalidad puede practicarse a pedido de parte, pero también de oficio, esto es, por la propia iniciativa del juez. Al respecto, habla expresamente de un "deber" de practicar tal revisión.

Tal lineamiento es, naturalmente, de honda significancia. Si debe ser ejercitado de oficio, y si siempre corresponde asegurar el "efecto útil" de la Convención Americana sobre derechos humanos, una consecuencia de ello es que el control podría practicarse hasta el momento mismo en que el juez debe resolver la litis donde debiera aplicarse la norma opuesta al Pacto, a fin, precisamente, de inaplicarla.

La directriz de la Corte Interamericana obliga al juez local a practicar directamente el control de convencionalidad, ${ }^{10}$ en el sentido que ese oficio no necesita estar autorizado por la Constitución o por las autoridades domésticas, todo ello sin perjuicio de lo que ya hemos apuntado sobre la competencia para hacerlo. Más todavía: si una norma local, constitucional o subconstitucional, intentara impedir el control de convencionalidad al juez apto para realizar control de constitucionalidad, esa regla concluiría necesariamente "inconvencional", por oponerse, como veremos, a la jurisprudencia de la Corte Interamericana de Derechos Humanos (ver infra, parágrafo VIII).

Como observación adicional, corresponde destacar que a partir de la aplicación del control de convencionalidad por los jueces nacionales, se incrementa notoriamente su carga laboral, dado que tendrán que conocer en detalle la jurisprudencia sentada por la Corte Interamericana de Derechos Humanos, y proyectarla en los fallos que emitan, a fin de realizar dicho control.

Un asunto importante es el del momento para practicar el control de convencionalidad. En "Trabajadores cesados del Congreso", la Corte encauza dicha revisión según las reglas procesales pertinentes y las pautas vigentes en cada Estado sobre admisibilidad y procedencia. Hay, pues, una significativa derivación a la normatividad local, circunstancia que puede dar lugar a distintas respuestas jurídicas según el país y el tipo de proceso donde se lo practique. Lo importante es que no puede ejercitarse a tontas y a locas, sino dentro de un marco ya reglado; pero también, que debe hacerse.

Es factible que esto obligue algunas veces a los jueces locales a concebir creativamente soluciones nuevas, como alertamos cuando nos referimos al ente

\footnotetext{
${ }^{10}$ En el sentido del control de convencionalidad como control directo por los jueces nacionales, ver GARCíA Ramírez, Sergio, (2009), nota 1, p. 344.
} 
competente (supra, parágrafo IV). De cualquier manera, como el control tiene que consumarse incluso de oficio, el juez podría articularlo al resolver en definitiva una litis, aunque antes no se hubiese planteado.

\section{EL MATERIAL NORMATIVO CONTROLADO}

En principio, las dos sentencias clave que citamos ("Almonacid Arellano" y "Trabajadores cesados del Congreso"), someten al control de convencionalidad a las leyes incompatibles con el Pacto de San José de Costa Rica. Pero también refieren a las normas jurídicas internas, o simplemente a las normas internas, que se encuentren en igual situación de confrontación.

Por ello, en definitiva, cualquier regla jurídica doméstica (ley, decreto, reglamento, ordenanza, resolución, etc.), está sometida al control de convencionalidad. En Estados donde la doctrina jurisprudencial establecida por la Corte Suprema o el Tribunal Constitucional es obligatoria para los tribunales inferiores, ella también reviste materialmente condición de norma y, por ende, está captada por dicho control.

Incluso, está igualmente comprendida la Constitución nacional, no exceptuada en los veredictos aludidos. En este tramo tan importante de la doctrina que referimos, se parte tácitamente del supuesto de que el Pacto de San José de Costa Rica se encuentra por encima de todo el ordenamiento jurídico del Estado, sin omitir a la propia Constitución. El Pacto asume así, agrade o no esta conclusión, y por más que por algunos se la quiera edulcorar, condición de supraconstitucionalidad. Por ello, como en el caso de "La última tentación de Cristo", por ejemplo, la Corte Interamericana de Derechos Humanos reclamó a Chile modificar una cláusula de la Constitución local opuesta al Pacto, como efectivamente se hizo después. ${ }^{11}$ Volvemos sobre el asunto infra, en el parágrafo IX.

Desde luego, esta afirmación no será fácil de digerir por Estados para los cuales los tratados internacionales son leyes comunes, o aquellos otros en los que, en el mejor de los casos, resultan superiores a las leyes ordinarias, pero siempre inferiores a la Constitución. Quizá es más potable para naciones donde el Pacto de San José de Costa Rica cuenta con rango constitucional, pero aun así el problema subsiste, porque el control de convencionalidad está partiendo del supuesto de que el Pacto predomina sobre la Constitución, y no que es igual a ella.

Este nudo de la cuestión será, probablemente, el talón de Aquiles de la doctrina del control de convencionalidad. Pero en definitiva, bueno es que alguna vez se plantee y resuelva nítidamente. A nuestro entender, el conflicto debe dilucidarse

${ }^{11}$ Cfr. García Ramírez, Sergio, (coord.) (2001), pp. 764 y 767. 
partiendo del supuesto de que, axiológicamente, el bien común internacional (en este caso, el bien común regional) se erige como un valor superior al bien común nacional, ${ }^{12}$ y que tal cotización, planteada en la esfera de la estimativa jurídica, obliga en la dimensión normativa del derecho a preferir al Pacto sobre la Constitución. En todo caso, al Estado que no esté dispuesto a pagar ese precio para sumarse al proceso integrativo en el ámbito de los derechos humanos, le quedará la salida honrosa (si decide afrontar el costo jurídico y político que ella también tiene) de denunciar al Pacto de San José de Costa Rica, e irse de él según el trámite de retiro. Lo que no parece honroso es ratificar el Pacto y después argumentar que no cumple alguna de sus cláusulas porque ella no coincide con su Constitución.

\section{EL MATERIAL NORMATIVO CONTROLANTE}

El "control de convencionalidad", como su nombre lo indica, procura hacer prevalecer la Convención Americana sobre Derechos Humanos, o Pacto de San José de Costa Rica, sobre las reglas locales que se le oponen. La cuestión merece ciertas explicitaciones:

a) es profundamente importante advertir que la Corte Interamericana destaca que el material controlante no consiste exclusivamente en las normas del Pacto, sino también en la interpretación dada a esas reglas por la Corte Interamericana. "Almonacid Arellano", además, no distingue entre interpretaciones vertidas en sentencias (parte resolutiva y fundamentos), o en opiniones consultivas. En otras palabras, el material normativo controlante está conformado por las cláusulas del Pacto de San José de Costa Rica, más la exégesis que de ellas ha hecho la Corte Interamericana.

b) de hecho, esta tesis importa una interpretación mutativa por adición realizada sobre el Pacto por la Corte Interamericana, en su condición de intérprete definitiva del mismo (art. 67). El tribunal ha agregado algo al contenido inicial del Pacto, aunque el texto literal de éste no ha variado. ${ }^{13}$ Así, un Estado puede verse obligado por la doctrina sentada por la Corte Interamericana de Derechos Humanos, en una causa en la que él no ha sido parte, ni obviamente tenido oportunidad para alegar en pro de una interpretación diferente a la formulada en aquel expedien-

\footnotetext{
${ }^{12}$ Desarrollamos esta idea en SAGÜés, Néstor Pedro (1966), pp. 214 y ss., inédita, adonde nos remitimos.

${ }^{13}$ Respecto a la interpretación constitucional mutativa, por adición, sustracción o mixta, nos remitimos a SAGǗs, Néstor Pedro, (2006), pp. 42 y siguientes. Respecto al tema que nos preocupa, Hitters advierte, con razón, que ninguna cláusula del Pacto de San José confirió efectos vinculantes a la jurisprudencia de la Corte Interamericana, más allá del caso concreto. Cfr. Hitters, Juan Carlos, (2008), nota 2, p. 1169.
} 
te. ${ }^{14}$ Paralelamente, la interpretación formulada por la Corte Interamericana va a tener de hecho el mismo valor que la letra del Pacto, e incluso será superior a la redacción de éste, porque como intérprete final del mismo fija la superficie y el alcance de sus cláusulas escritas.

c) en conclusión, la Corte Interamericana de Derechos Humanos, merced a la doctrina del control de convencionalidad, ha afirmado como obligatoria una tesis semejante, de algún modo, al stare decisis, o valor del precedente estadounidense de su Corte Suprema de Justicia, doctrina creada en aquel país también sin un texto constitucional expreso que la haya sostenido. ${ }^{15} \mathrm{O}$ si se prefiere, asume los roles de una Corte de Casación supranacional en derechos humanos, en aras de uniformar la interpretación de los derechos de esa índole emergentes del Pacto de San José de Costa Rica. Y ello importa, inexorablemente, una sensible reducción de las facultades de los jueces nacionales en materia de control de constitucionalidad y de interpretación de los derechos personales. De aquí en más ya no son libres de descifrar esos derechos a su independiente leal saber y entender, sino que deben comprenderlos con el significado que hasta ahora les ha dado, y les dará en el futuro la Corte Interamericana. Asimismo, tendrán que "leer" los derechos constitucionales locales en consonancia con esas directrices, como puntualizamos infra, en el parágrafo X.

d) pero, además, las sentencias que comentamos se expresan en términos más generales, y refieren a la hipótesis de que un Estado haya ratificado "...un tratado como la Convención Americana” (la bastardilla es nuestra). La doctrina, pues, se aplicaría con relación a cualquier tratado; el Pacto de San José de Costa Rica sería solamente una muestra o ejemplo de material normativo controlante.

Queda la incógnita de determinar si en verdad la Corte Interamericana ha querido conscientemente proyectar la teoría del control de convencionalidad a

\footnotetext{
${ }^{14}$ Un problema paralelo que se presenta en esta cuestión, es cuando la Corte Interamericana ha definido algún artículo del Pacto de San José de Costa Rica, en un litigio concreto, admitiendo en esa interpretación el uso de la doctrina del margen de apreciación nacional que, como se sabe, distingue en todo derecho un núcleo "duro" o "fundamental", no reducible ni negociable, y otro segmento, más maleable, donde los Estados pueden introducir variantes de contenido atendiendo razones, por ejemplo, de buenas costumbres, moral pública, interés social, etc., diferentes de nación en nación. Si la Corte Interamericana de Derechos Humanos ha sentado en una causa una tesis recurriendo al "margen de apreciación nacional" de un país puntual, tal doctrina, a la medida para ese Estado, no debería obligar a los demás. En otras palabras, la obligación de seguimiento a las interpretaciones formuladas por la Corte Interamericana, obliga a distinguir entre "interpretaciones en lo fundamental" o "esencialistas", o "definicionales", e "interpretaciones contingentes", o "ad hoc", de valor solamente (en principio) para el caso en donde fueron formuladas. Agradezco en este tema los aportes conceptuales de Rodolfo O. Vigo. Para la doctrina del margen de apreciación nacional en la interpretación constitucional, me remito a SAGỨs, Néstor Pedro, (2006), nota 11, pp. 222 y ss.

${ }^{15}$ Sobre el valor del precedente en Estados Unidos y en Argentina, ver SAGÜÉs, Néstor Pedro, (2009), pp. 261 y ss.
} 
cualquier tratado, como se desprende de algún voto del tribunal. ${ }^{16}$ Es un punto que merece en el futuro una pronta y clara explicitación por parte de dicha Corte, ya que involucra temas tales como si todos los tratados de derechos humanos tienen para los países ratificantes del Pacto de San José de Costa Rica rango supraconstitucional, y si es obligación -o no- de todos los jueces del área inaplicar, incluso de oficio, las reglas locales que los contradigan.

En principio, a la Corte Interamericana no le tocaría tutelar a otros tratados, fuera del Pacto de San José de Costa Rica y a los instrumentos que a él se adosen jurídicamente, frente a posibles infracciones provocadas por el derecho interno del Estado. Pese a ello, la función consultiva de la Corte Interamericana de Derechos Humanos puede referirse también a la interpretación de cualquier tratado internacional concerniente a la protección de los derechos humanos en los Estados americanos (art. 64 del Pacto).

En definitiva, resulta obligado, por elementales razones de seguridad jurídica, que la Corte Interamericana disipe con urgencia la cuestión.

\section{LOS EFECTOS DEL CONTROL}

El objetivo del "control de convencionalidad" es determinar si la norma nacional enjuiciada a través de la Convención Americana sobre Derechos humanos, es o no "convencional", esto es, acorde con tal Convención (Corte Interamericana de Derechos Humanos, "Boyce y otros vs. Barbados", considerando 78). Si lo es, el juez la aplica. Caso contrario, no, por resultar "inconvencional". Se trata, como se ha apuntado, de un análisis de confrontación normativa. ${ }^{17}$

Dicha "inconvencionalidad" (o, si se prefiere, "anticonvencionalidad") importaría una causal de invalidez de la norma así descalificada, por carecer "desde un inicio" de "efectos jurídicos" (doctrina de "Almonacid Arellano"). La inconvencionalidad produce un deber judicial concreto de inaplicación del precepto objetado. ${ }^{18} \mathrm{Y}$ si éste no tiene, desde su inicio, vigor jurídico, equivaldría a reputarlo

\footnotetext{
${ }^{16}$ Así, el voto razonado del juez Sergio García Ramírez, en el caso "Trabajadores cesados del Congreso vs. Perú”, donde estima que la misma función de control de convencionalidad puede expandirse, aparte del Pacto de San José de Costa Rica, a instrumentos como el Protocolo de San Salvador, la convención de Belem do Pará para la erradicación de la violencia hacia la mujer, Convención Interamericana sobre Desaparición forzada de personas, etc., en aras de lograr que haya conformidad entre los actos internos de un Estado, y los compromisos internacionales contraídos por él. Ver Salinas, Pablo G., "Cumplimiento de las resoluciones de la Corte IDH a la luz del caso Penitenciarías de Mendoza”, en Albanese, Susana (coord.), (2008), nota 2, p. 236.

${ }^{17}$ Rey Cantor, Ernesto, (2008), nota 1, p. 46.

${ }^{18}$ En el sentido que los jueces nacionales deben abstenerse de aplicar las normas locales opuestas a la convención, en base al control de convencionalidad, ver recientemente los casos Ramírez y Raxcacó, de 9 de mayo de 2008, Corte Interamericana de Derechos Humanos, considerando 63. Por su parte, Frédéric Sudré estima
} 
inexistente, ex tunc, con efectos retroactivos, para la solución del litigio donde es así enjuiciado.

Aparentemente, el "control de convencionalidad" es asimilable en sus efectos al resultado del control de constitucionalidad ceñido al caso concreto, con efectos inter partes. La norma repudiada es inaplicada, pero no derogada. Por resultar incompatible con el derecho superior (en este caso, la Convención Americana), no se la efectiviza.

Una duda emerge si el órgano que realiza el control de convencionalidad posee, según el derecho constitucional del país del caso, y en materia de control de constitucionalidad, competencia para abolir o derogar a la norma inconstitucional. ¿Podría en tal caso nulificar o derogar erga omnes a, por ejemplo, una ley "inconvencional"?

La Corte Interamericana de Derechos Humanos no ha aclarado este subtema. Formalmente, a ella le basta con que, en el caso puntual, no se efectivice la norma local opuesta a la Convención Americana sobre derechos humanos, reputada "inconvencional" por los jueces domésticos. Sin embargo, si el órgano control de constitucionalidad, por semejanza a sus funciones en la materia, tiene en el país del caso autoridad para derogar a la regla inconstitucional, desde luego que el sistema interamericano no se ofendería si también elimina, por analogía y con resultados erga omnes, a la norma "inconvencional".

\section{CONTROL DE CONSTITUCIONALIDAD Y CONTROL DE CONVENCIONALIDAD}

En una primera aproximación, se puede afirmar que se trata de dos dispositivos distintos, con objetivos diferentes: uno intenta afirmar la supremacía de la constitución nacional; el otro, la del Pacto de San José de Costa Rica.

Tienen en común manejar -en el fondo- un mismo argumento: la invalidez de la norma inferior opuesta a la superior. En el caso de confrontación entre una ley y la constitución, ello es evidente. En el supuesto de oposición entre una cláusula de la constitución y la Convención Americana (Pacto de San José de Costa Rica), el asunto es más discutido, pero de todos modos, si el Estado debe cumplir con la convención a todo costo, y no puede alegar su constitución para incumplir al Pacto, esto provoca, como resultado concreto final, que el pacto está jurídicamente por

que el resultado del control de convencionalidad, cuando descalifica a la norma opuesta a la Convención, significa "paralizar la aplicación de una ley aun cuando ella haya sido juzgada conforme a la Constitución...". Cfr. Sudré, Frédéric, (2005), pp. 198 y ss., cit. por Albanese, Susana, (2008), nota 2, p. 23. La referida "paralización" equivale jurídicamente, nos parece, a una "inaplicación”, concepto éste más preciso en derecho. En cuanto que el Poder Judicial debe abstenerse de aplicar cualquier normativa contraria a la Convención Americana de derechos humanos, ver también LucchetTI, Alberto J., "Los jueces y algunos caminos del control de convencionalidad”, en Albanese, Susana (coord.), (2008) op. cit., nota 2, p. 144. 
encima de la Constitución. En efecto, la consecuencia del control de convencionalidad, es que la regla constitucional que lesiona al Pacto debe quedar inaplicada, o si se prefiere, de aceptarse la expresión de Sudré19, "paralizada" (lo mismo acaece, desde luego, con las normas subconstitucionales violatorias del pacto).

Si se desea ampliar el tema, desde otra perspectiva, puede constatarse que el Pacto puede lesionar jurídicamente a la Constitución, en tanto que su derecho puede acarrear la inaplicación de la regla constitucional que se le oponga, o exigir la modificación de ella (téngase presente, una vez más, el caso "La última tentación de Cristo"). ${ }^{20}$ Por el contrario, según el control de convencionalidad, la Constitución no puede válidamente lesionar al Pacto. Si ello no implica superioridad de la convención sobre la Constitución, francamente no sabemos cómo denominar de otro modo a tal estado de cosas.

Por todo ello, también en principio, una norma subconstitucional nacional debe superar dos vallas: la del control de constitucionalidad, y la del control de convencionalidad. Si cae por alguna de ellas, resulta inaplicable. No es suficiente, entonces, con que una regla local sea constitucional. También debe ser "convencional".

Esto, como regla. Sin embargo, pueden darse situaciones especiales. Supóngase que una ley que viole la Constitución nacional, pero coincida con el Pacto de San José. Tómese, siempre como conjetura, el caso del derecho de réplica, rectificación o respuesta, expresamente enunciado en el Pacto (art. 14), pero hipotéticamente negado por una Constitución..$^{21}$ Si se dictara allí una ley reglamentaria del mismo, ella resultaría inconstitucional, pero en cambio, sería "convencional". Como aquella cláusula constitucional negatoria de un derecho de fuente convencional padecería de "inconvencionalidad", la ley reglamentaria del derecho, en el caso presunto que comentamos, concluiría válida, por la superioridad del Pacto sobre la Constitución, conforme la doctrina del "control de convencionalidad". ${ }^{22}$

De esto podría desprenderse la siguiente consecuencia: la norma nacional subconstitucional que efectivice un derecho emergente del Pacto, es jurídicamente

${ }^{19}$ Cfr. Sudré, Frédéric., (2004), nota 16, pp. 198 y ss.

${ }^{20}$ García Ramírez, Sergio, (coord.) op. cit., nota 9, p. 764.

${ }^{21}$ En Argentina, algunas constituciones provinciales han prohibido el ejercicio del derecho de réplica. Ver SAGÜÉs, Néstor Pedro, (2008), p. 149.

${ }^{22}$ Esta situación no debe llamar a asombro, ya que registra antecedentes en materia de control de constitucionalidad. Por ejemplo, si una ley negase arbitrariamente un derecho a determinados sujetos, vulnerando el principio de igualdad (por ejemplo, al denegar el beneficio de las jubilaciones a los ciudadanos provenientes de determinado Estado), resultaría inconstitucional; mientras que el decreto reglamentario de la referida e hipotética ley, que otorgase en cambio la jubilación a todos, omitiendo la cláusula legal restrictiva, pese a violar la gradación jerárquica ley-decreto, resultaría de todos modos constitucional, y correspondería aplicarlo, por hacer prevalecer el principio constitucional de igualdad frente a la ley que lo infringía. 
válida, aunque colisione con una regla constitucional local que impida la vigencia del derecho emergente del Pacto.

En síntesis, el "control de convencionalidad" se perfila a la postre, en los veredictos que citamos, como un "control de supraconstitucionalidad", quiéraselo o no llamar así.

\section{LA INTERPRETACión DE LA CONSTITUCIÓN, "CONFOrme" CON la CONVENCIÓn AMERICANa DE DEREChos humanos}

Hasta ahora, el control de convencionalidad parece operar como una suerte de rayo exterminador de normas locales. Esto vendría a ser la "faceta destructiva" de ese control. Pero avizoramos otra, de tipo "constructivo" o positivo.

Si se acepta la premisa señalada en el último párrafo, no solamente habría que reputar inválidas (por "inconvencionales") las normas constitucionales y subconstitucionales opuestas al Pacto de San José de Costa Rica, sino que también deberían, en todo lo posible, interpretarse "de acuerdo", o "de conformidad" a dicho Pacto. Ello es así por analogía con la doctrina de la interpretación de las normas subconstitucionales, "conforme" con la Constitución. ${ }^{23}$ También, deberían, asimismo en todo lo posible, ser interpretadas las normas domésticas en consonancia con la jurisprudencia de la Corte Interamericana de Derechos Humanos.

Consecuentemente, si una cláusula de una constitución nacional (o una norma subconstitucional) permite por ejemplo dos o tres interpretaciones, el operador deberá preferir la que coincida, y no la que se oponga, a la Convención Americana de derechos humanos. A contrario sensu, ello significa que deberá desechar las interpretaciones de la norma constitucional o subconstitucional, que resulten incompatibles con la Convención Americana, o con la interpretación dada a esta última por la Corte Interamericana de Derechos Humanos.

Mediante el uso de la interpretación "conforme", el operador puede a menudo evitar la declaración de invalidez, por "inconvencionalidad”, de normas constitucionales o subconstitucionales prima facie colisionantes con el Pacto de San José de Costa Rica. Se trata de un dispositivo práctico de rescate de esas normas, que podrán permanecer como válidas, en tanto y en cuanto se seleccione, para aplicarlas, sus interpretaciones posibles "conformes" con la Convención Americana, y se descarten las interpretaciones conflictivas con la misma Convención, o con la jurisprudencia de la Corte.

El 23 de noviembre de 2009, finalmente, en "Rosendo Radilla Pacheco", considerandos 338 a 340, la Corte Interamericana de Derechos Humanos recepcionó

${ }^{23}$ Cfr. Díaz Revorio, F. Javier, (2003); Pérez Luño, Antonio E., (1984), p. 282. 
la doctrina de necesidad de la interpretación del derecho nacional, "conforme" con el Pacto de San José de Costa Rica, y con la jurisprudencia de dicho Tribunal sobre el mismo.

Abonan también este criterio las sensatas observaciones de Humberto Nogueira Alcalá, en el sentido que conforme al principio de buena fe, cabe presumir (como regla), que el legislador local no ha querido contradecir al Pacto de San José de Costa Rica, y que "la legislación interna debe considerarse conforme al derecho convencional, salvo cuando exista una incompatibilidad directa e insuperable entre ambos". ${ }^{24}$

\section{El FUTURO DEL CONTROL DE CONVENCIONALIDAD}

La Corte Interamericana de Derechos Humanos ha hecho una fuerte apuesta al formular, en términos bastante duros, la doctrina del control de convencionalidad. Habrá que ver ahora si se consolida como derecho consuetudinario.

Cabe vaticinar que no será fácil la aceptación incondicional de esa tesis, por parte de las cortes supremas y tribunales constitucionales nacionales. Por ejemplo, sostener la invalidez de las reglas constitucionales domésticas opuestas al Pacto, con más el deber de inaplicarlas ex officio en el perímetro nacional por los propios jueces locales, provocará quizá cortocicuitos de no rápido arreglo.

Siguiendo a Konrad Hesse, ${ }^{25}$ cuando discurre sobre la fuerza normativa de la Constitución, podría sostenerse que el éxito de la doctrina del control de convencionalidad dependerá de dos factores:

a) por un lado, de la efectivización sensata, prudente y legítima que haga la Corte Interamericana de Derechos Humanos de tal doctrina. Antes de pronunciar la "inconvencionalidad" de, por ejemplo, una regla constitucional nacional, la Corte de referencia deberá también agotar todos los recursos útiles para interpretarla conforme con la Convención Americana de Derechos Humanos, partiendo de lo que podríamos llamar una "presunción de convencionalidad" (juris tantum, desde luego), del derecho doméstico, conforme las ya apuntadas ideas explicitadas al final del parágrafo anterior. Y en caso de duda, conforme a tal presunción, habrá que optar por la validez, y no por la invalidez, del derecho nacional.

Otro indicador de la subsistencia o crisis de la doctrina es tributario del contenido intrínseco de las sentencias de la Corte Interamericana. Si las interpretaciones que ella haga del Pacto de San José resultan acertadas y cuentan con una convincente dosis de legitimidad, el peso axiológico de tales exégesis provocará

\footnotetext{
${ }^{24}$ Nogueira Alcalá, Humberto, (2007), p. 177, con un excelente desarrollo de esta sentencia.

${ }^{25}$ Hesse, Konrad, (1983), pp. 68 y ss.
} 
aceptación y consenso. En cambio, si dichas interpretaciones suscitan disconformidad y cuestionamientos, ya por sus defectos jurídicos, ya por una eventual manipulación ideológica del derecho de los derechos humanos, ya por ignorar las posibilidades y límites de la realidad, los parámetros que así establezca la Corte Interamericana debilitarán el control de convencionalidad que ella procura exigir. Conectado con lo dicho es la conveniencia de interpretar la Convención Americana, dentro de lo posible y razonable, atendiendo las particularidades locales, según la doctrina del margen de apreciación nacional. ${ }^{26}$ Tal contemplación, que evita autismos normativos o "internacionalismos salvajes" (como alguna vez se los denominó), afianza, en vez de debilitar, la solidez y eficacia del Pacto de San José de Costa Rica.

b) el buen suceso de la doctrina del control de convencionalidad está condicionado, igualmente, por la voluntad de seguimiento que tenga por parte de los tribunales nacionales, en particular de sus órganos supremos. En el caso de Argentina, la Corte Suprema de Justicia prestó una adhesión explícita a aquella doctrina, en "Mazzeo". ${ }^{27}$ Pero habrá que examinar con detenimiento cuál es la actitud de las demás cortes, salas y tribunales constitucionales del subcontinente.

\section{XiI. Recapitulación. Conclusiones}

La doctrina del "control de convencionalidad", bien instrumentada, puede ser una herramienta provechosa para asegurar la primacía del orden jurídico internacional de los derechos humanos, y edificar un "ius commune" en tal materia, en el área interamericana.

Se trata de una innovación muy significativa, quizá copernicana, que:

a) provoca una interpretación mutativa por adición al Pacto de San José de Costa Rica;

b) recorta el margen de acción de los jueces nacionales en materia de control de constitucionalidad y de interpretación del Pacto y de las constituciones locales;

c) parte del supuesto de la primacía del Pacto sobre las constituciones domésticas, cuestión harto polémica pero que es positivo que se defina de una vez;

d) posee una vertiente "destructiva" o "saneadora" (no aplicar las reglas locales opuestas al Pacto de San José de Costa Rica y a la interpretación de la Corte Interamericana), y otra "constructiva", tan importante como la primera (interpretar las normas domésticas en consonancia con el Pacto y con la Corte Interamericana);

\footnotetext{
${ }^{26}$ Sobre la doctrina del "margen de apreciación nacional" nos remitimos a SAGÜÉs, Néstor Pedro, La interpretación judicial de la Constitución, (2006), nota 11, pp. 222 y ss.

${ }^{27}$ Corte Suprema de Justicia de la Nación Argentina, Jurisprudencia Argentina, Buenos Aires, 2007, t. III p. 573 , considerando 21.
} 
e) no explicita claramente su aplicación con la vigencia de la doctrina del margen de apreciación nacional;

f) tampoco delimita con cuidado si es obligatoria respecto de todos los tratados internacionales sobre derechos humanos, y si todos ellos tienen primacía sobre las constituciones locales;

g) no ha explicado con nitidez qué ocurre con los jueces nacionales que no pueden ejercer control de constitucionalidad, en el sentido de si también deberían, o no, practicar el de convencionalidad.

Para afirmarla en el futuro, y lograr que se fragüe como derecho consuetudinario, bueno es que la Corte Interamericana de Derechos Humanos la encuadre con mayor corrección y que cuide la calidad y prudencia de sus veredictos. Solamente en la medida en que más se autoexija, podrá a su vez exigir más a las cortes nacionales.

XIII. EL CONTROL DE CONVENCIONALIDAD PRACTICADO POR LA PROPIA CORTE INTERAMERICANA

Hasta el momento se ha discurrido acerca del "control de convencionalidad" como un deber de los jueces nacionales, según las directrices de la Corte Interamericana de Derechos Humanos. Pero ella también lo practica materialmente, cuando reputa incompatibles con el Pacto de San José de Costa Rica a ciertas cláusulas constitucionales (recuérdese, v. gr., "La última tentación de Cristo"), ${ }^{28} \mathrm{O}$ leyes nacionales opuestas al Pacto.

Últimamente se ha advertido, con agudeza, que en ciertos veredictos ("La Cantuta vs. Perú", v. gr.), la Corte Interamericana habría incluso nulificado normas nacionales, como leyes de amnistía, con efectos erga omnes, comportándose así como un verdadero Tribunal Constitucional nacional..$^{29}$ Aunque profundizaremos esta temática en otro estudio, cabe anticipar que una competencia derogatoria de reglas domésticas no está contemplada por el Pacto de San José de Costa Rica, e importaría, de consolidarse en el futuro, otra interpretación mutativa por adición del Pacto, por cierto que muy cuestionable. Una cosa es que la Corte Interamericana repute jurídicamente inválidos a esos preceptos, y resuelva inaplicarlos por infringir el Pacto, y otra, que esté habilitada para abolirlos. Felizmente, la sentencia pronunciada en el caso que citamos solamente parece inclinarse a sostener que, en general, los poderes públicos del Perú no deben aplicar las normas de amnistía incompatibles con el Pacto de San José de Costa Rica.

${ }^{28}$ Cfr. García Ramírez, Sergio, (coord.) (2001), nota 9, p. 764.

${ }^{29}$ THiers, Juan Carlos, (2008), nota 2, p. 1169. 


\section{BiBLIOGRAFÍA}

AlbANese, Susana, (2008) "La internacionalización del derecho constitucional y la constitucionalización del derecho internacional”, en Albanese, Susana, (coord.), El control de convencionalidad, (Buenos Aires, Ediar).

DíAz Revorio, F. Javier, (2003), La interpretación constitucional de la ley. (Lima, Palestra).

García Ramírez, Sergio, (coord.) (2001). La jurisprudencia de la Corte Interamericana de Derechos Humanos, (México, UNAM).

García Ramírez, Sergio y Morales, Julieta, (2009) “La jurisprudencia de la Corte Interamericana de Derechos Humanos en el período 2007/2009”, Anuario Iberoamericano de Justicia Constitucional núm. 13, (Madrid, Centro de Estudios Políticos y Constitucionales).

García Ramírez, Sergio, (2009), Cuestiones jurídicas en la sociedad moderna, Cuadernos del Seminario de Cultura Mexicana, México, p. 344.

Hesse, Konrad, (1983), Escritos de derecho constitucional, trad. por Pedro Cruz Villalón, (Madrid, Centro de Estudios Constitucionales).

Hitters, Juan Carlos, (2008), “¿Son vinculantes los pronunciamientos de la Comisión y de la Corte Interamericana de Derechos Humanos? Control de constitucionalidad y de convencionalidad", La Ley, Buenos Aires, t. E.

Lucchetti, Alberto J. (2008). "Los jueces y algunos caminos del control de convencionalidad”, en Albanese, Susana (coord.),(2008), El control de convencionalidad, (Buenos Aires, Ediar).

Nogueira Alcalá, Humberto, (2007), "Los desafíos de la sentencia de la Corte Interamericana en el caso Almonacid Arellano", en Revista de Derecho, Universidad Católica, Montevideo, No 02, 2007.

Pérez Luño, Antonio E., (1984). Derechos humanos, Estado de Derecho y Constitución, (Madrid, Tecnos).

Rey CANTOR, Ernesto, (2008), Control de convencionalidad de las leyes y derechos humanos, (México, Porrúa).

Pérez Tremps, Pablo. (2005), Escritos sobre justicia constitucional, (México, Porrúa). SAGÜÉs, Néstor Pedro, (1966), Integración y desintegración del concepto de soberanía, Tesis doctoral. (Madrid, Facultad de Derecho, Universidad Complutense), inédita.

SAGÜÉs Néstor Pedro, (1978), Jean Bodin y la escuela española, (Rosario, Facultad de Derecho y Ciencias Sociales de la Universidad Católica Argentina).

SAGÜÉs, Néstor Pedro, (2006), La interpretación judicial de la Constitución, 2a ed., (Buenos Aires, LexisNexis). 
SAGÜÉs, Néstor Pedro, (2008), Censura judicialy derecho de réplica, (Buenos Aires, Astrea).

SAGÜÉs, Néstor Pedro, (2009). Derecho Procesal Constitucional. Logros y obstáculos, Tribunal Constitucional del Perú, Lima.

Salinas, Pablo G. (2008), "Cumplimiento de las resoluciones de la Corte IDH a la luz del caso Penitenciarías de Mendoza”, en Albanese, Susana (coord.), (2008), El control de convencionalidad, (Buenos Aires, Ediar).

Sudré, Frédéric., (2004), A propos du “dialogue de juges" et du controle de conventionnalité, (París, Pedone).

Sudré, Frédéric. (2005). Droit européen et international des droits de l'homme, 7a ed., (París, Presses Universitaires de France). 
